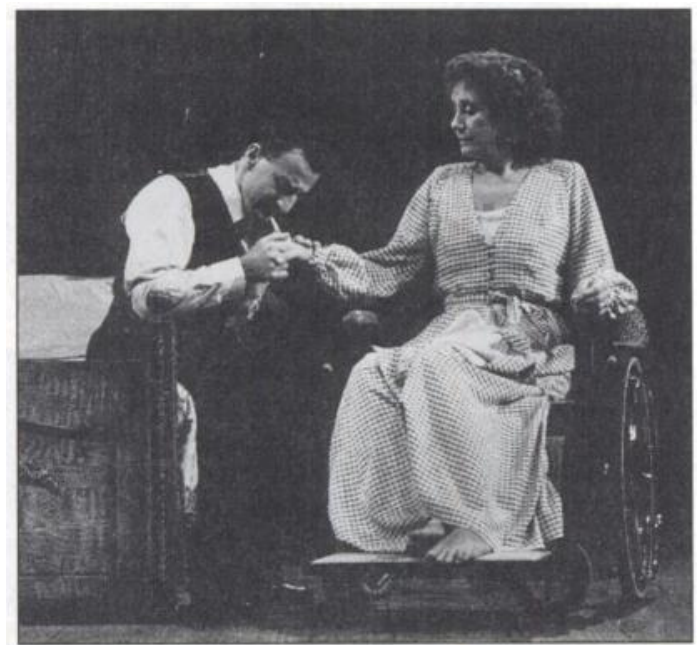

Henry Goodman (Philip Gellburg) and Margot Leicester (Sylvia Gelliburg) in 'Broken Glass' Photograph Alastair Muir. Royal National Theatre.

Military Academy. In the recurring dream which she describes to Dr Hyman, Sylvia is stalked and attacked by a man in uniform. Although initially she says she does not see the man's face, with Dr Hyman's insistence she eventually agrees it is her husband

The image of broken glass serves as a fitting metaphor to convey the fragmentation of a society in an economic depression, whose moral and spiritual fabric has been corroded. There is a symmetry between the use of denial on a personal and public level, and Sylvia's paralysis mirrors the insidious and stupefying inertia in her apparently more resilient contemporaries. Her symptoms challenge those around her to re-focus and in the denouement, her Philip finds himself on his deathbed following a heart attack, a broken man, frightened and seeing his life as a failure. He has lost the woman he adored, and wasted his energy all these years "foreclosing Brooklyn", only to be spurned by his ungrateful employer when he lost him the coveted site for a new clubhouse.

The excellent performance of Henry Goodman as the pent-up Gellburg dominates this production - the stiff outer composure barely containing his rage. Uncomfortably, the portrayal of Sylvia is less affecting. One wonders if this is due to casting, Miller's relative weakness in fleshing out his female characters, or a reflection of the reflex frustration the psychiatrist can feel when confronted with the hysteric.

Broken Glass has also had an off-stage denouement. After writing the play, Miller discovered that sudden paralysis among Jews in America became unusually frequent around this time.

Roisin Kemp, Research Worker, Academic Department of Psychological Medicine, King's College Hospital, and Honorary Senior Registrar, Maudsley Hospital, London SE5

\title{
Corrigendum
}

In the fourth paragraph of the article The films of Wim Wenders' (Psychiatric Bulletin, November

1994, 18, 689), Solveig Donmartin should have been referred to as Wenders' muse.

\section{Ancient remedies}

Melancholly. Eat oft Cream of Tarter mixt with Honey or Treacle. Meditate on your Sufferings.

Madness. Hold him under water till he is almost drown'd, then put him into Bed in a dark Room. Let his Diet be only Milk pottage and Water.

Raging madness. Keep the head close shaved, and wash it often with strong vinegar. Or, apply to the head often cloths dipped in very cold water.
In case a man be lunatic. Take skin of a mereswine or porpoise, work it into a whip, swinge the man therewith, soon he wil be well. Amen.

Taken from Curlous Cures (Steyning Museum Trust).

Supplied by L.D. CULlifORD, Hove Community Mental Health Centre, Hove BN3 4AG 